\title{
Psychological and pedagogical aspects of increasing educational motivation
}

\author{
Nadezhda Efremova $^{1, *}$, Anastasia Huseynova ${ }^{1}$ \\ ${ }^{1}$ Don State Technical University, 1, Gagarina square, 344003, Rostov-on-Don, Russia
}

\begin{abstract}
Given scientific research is devoted to the consideration of factors influencing educational (learning) motivation. One such factor is the assessment of academic achievements. The difficulties of obtaining an objective assessment in educational practice are noted and possible ways to overcome them are shown, including through external (independent) standardized testing. Authentic assessment requires special training and the creation of an appropriate base, this problem can be solved in the form of organizational and methodological support of teachers by external professional centers providing assessment in the form of an educational audit. The data of external testing and subsequent questionnaires are presented, allowing to judge about changes in the educational motivation of school students in the assessment process. The need to identify the progress of individual achievements in the educational process requires the development and introduction of new assessment forms that create the confidence of students in assessments and affect educational motivation.
\end{abstract}

\section{Introduction}

The formation of educational motivation within the educational space is one of the central problems of modern education. Today, the expert community is unanimous in stating that the effectiveness of cognitive activity directly depends on the degree of motivation of participants to improve results. Speaking about the relevance of the study, one cannot but note a number of contradictions that arise during an in-depth analysis of the problem: insufficient motivation of students in the process of traditional assessment, due to the low level of confidence in the results of control; the lack of quality measuring materials and the experience of their development among teachers; the feasibility of using objective control data for the sound management of the educational process. In domestic practice, an effective system for assessing learning outcomes is in the process of formation, a search is being made for the most reliable means, methods and technologies of assessment for compliance with the standards of assessment activity recognized throughout the world.

In the scientific works of B. Bloom, a classification (taxonomy) of educational goals is given, taking into account the differences between solving problems and the position, thinking and feelings of students, their actions and thinking. It is noted that the ability to teach a person is determined by three areas of mental activity (domains): cognitive (cognitive), emotional-value (affective) and psychomotor [1]. Taxonomy provides the

\footnotetext{
${ }^{*}$ Corresponding author: nefremova61@donstu.ru
} 
ordering and interconnection of various types of cognitive and affective behavior. As a result of internal processes during the student's activity and internalization as a transformation of knowledge from subjective to objective, a metacognitive result is formed. The taxonomy shows possible approaches to solving the problems of managing the educational process to improve the quality of training and ensure authentic assessment activities. And the process of interaction with external structures becomes an internal regulator of the development of motivation.

Due to the affective component, the motivation of students to achieve a result has a significant impact on the success of training. Affective (emotional-value) areas include the goals of forming an emotional-personal attitude to the phenomena of the world, the formation of interests and inclinations, the experiencing of certain feelings, awareness and manifestation in activity, receptivity to certain phenomena and incentives. Positive goals and objectives of affective development emphasize the central attention to the upper categories of the emotional sphere of students, ensure the integration of values into the system and their interconnection through the entire spectrum of taxonomic categories of affective behavior in achieving results.

Three levels of skills are distinguished, respectively associated with three types of tasks, having a hierarchical relationship with the learning objectives and planned results: the needs and capabilities of society; level of student development; the possibilities of pedagogical science and practice [2]. Educational goals in the affective sphere contribute to the acquisition by students of such qualities as self-confidence, responsibility, respect, reliability and self-esteem. At present, educational results expressed in terms of competencies as generalized personality traits that reflect their ability to effectively solve professional or personally significant problems are becoming important for the entire world community. Achievement of competency-based goals and learning outcomes is largely ensured by cognitive means and a practical component, as well as a result of evaluative activities that provide feedback on the development of the content of academic disciplines $[3,4]$. In a more general way, we can talk about educational goals that have a hierarchical structure: goals that require mastering skills of a high level of complexity include goals that require fewer complex activities, which require the decomposition of both goals and planned results. Accordingly, the assessment process should be built in accordance with these goals and sub-goals of training.

If we talk about motivation, it should be noted that it is a complex, multifaceted and latent parameter of personality traits, depending on many external and internal factors [5]. Therefore, for its development, many different approaches are required that consider one or another side and the features of influence on it. First of all, we note the research of David McClelland, who divided all human needs into three large groups: power, success and involvement [6]. His motivation model focuses on the needs of higher levels. As a result of theoretical research and successful educational practices, a large amount of information has been accumulated on the methods of formation and development of educational motivation (Bozovic L.I., Davydov V.V., Elfimova N.V., Ilyin EP, Markova A.K. Matyukhina M.V., Maslow A., Orlov A.B., Fridman L.M., Jacobson P.M. et al.).

In the context of informatization, the forms and methods of the formation and development of motivation change, the concept of hybrid motivation developed using social networks has appeared [7]. Today, the Internet is practically unlimited. Modern youth spends a lot of time in networks and interacts with a large number of users, receiving and transmitting various information. This allows them to find interesting problems for each and their solutions, including for in-depth study of the educational disciplines of educational programs. At the same time, thanks and encouraging messages from users regarding their information stimulate the creation of an even more interesting information product. 
To intensify learning activities and increase students' motivation to study the content of disciplines in educational practice, various factors are used: interesting content of the material studied; positive atmosphere in the educational organization; respectful style of interaction among students; organization of individual and collective project activities; assessment, mutual evaluation and self-assessment of achievements; style of educational activity of the teacher; various forms of support, etc. [8, 9, 10].

Based on an analysis of the individual's behavior, B. Skinner (1987) formulated the theory of learning, proving that environmental influences determine behavior, and, consequently, motive, directly due to reinforcement from the external environment. The encouragement in Skinner's theory was called reinforcement, since it develops the most desirable behavior and operant conditioning, which can be used for self-control by creating certain incentives that cause appropriate actions [11].

One of the incentives is a positive assessment of achievements. Emotions and the pleasure of achieving and positive assessments among students are associated with confidence in the results of control, while negative emotions are caused by distrust in the assessment. Effective training leads to satisfaction, which is a factor in reinforcing the desire to achieve even better results. In this context, evaluation in the form of external testing, the results of which students trust more than traditional, plays an important role as a factor of external reinforcement, as well as a feedback method and an important incentive for realizing the goal of individual achievements [12, 13].

However, an analysis of studies shows that in the field of the impact of assessment on educational motivation, there are very few information sources, and the available ones do not affect the reasons for this influence. Therefore, in this work, it was important to experimentally determine how assessment and the forms of assessment activity influence the development of educational motivation of students, how stable this influence is.

\section{Results}

In the framework of this study, the factor of influence in independent assessment of educational achievements in the form of standardized testing on the student educational motivation was an interest. To do this, the center external to the school conducted standardized testing of school children in social studies as a form of mid-term assessment. The external center for testing the discipline of social studies is selected as one of the most popular subjects in the final state certification of graduates. Assessment of academic achievements in social science and the subsequent collection of questionnaire information on the factors of influence on educational motivation were carried out in the educational organization on the same sample of schoolchildren with an interval of one year (2019 grade 10, 2020 - grade 11). After testing, students were questioned on a wide range of issues, including the change in their educational motivation. Additionally, a survey was conducted of their parents to identify how they assess the change in motivation of their children after external (independent of school) testing.

The results in Fig. Table 1 shows that after a year, approximately one third of the participants reduced their achievements in social studies, approximately the same number confirmed the estimates, and the rest improved the results. Most likely, in the 11th grade, graduates focus their efforts on those subjects that they need to enter universities, while they are much less involved in other subjects. This factor largely determines the importance of the subject and efforts for its development [14]. Not for all participants in the experimental group, successes in social studies have "high stakes" when choosing a future profession, so many are reoriented to other disciplines, which is also an important motive.

Both in 2019 and in 2020, after testing, a survey was conducted of the same students and their parents about changes in educational motivation. According to the questionnaire, 
the majority of students and parents noted an increase in educational motivation after an independent assessment. The most powerful increase in motivation was shown by students themselves - from 73 to $86 \%$.

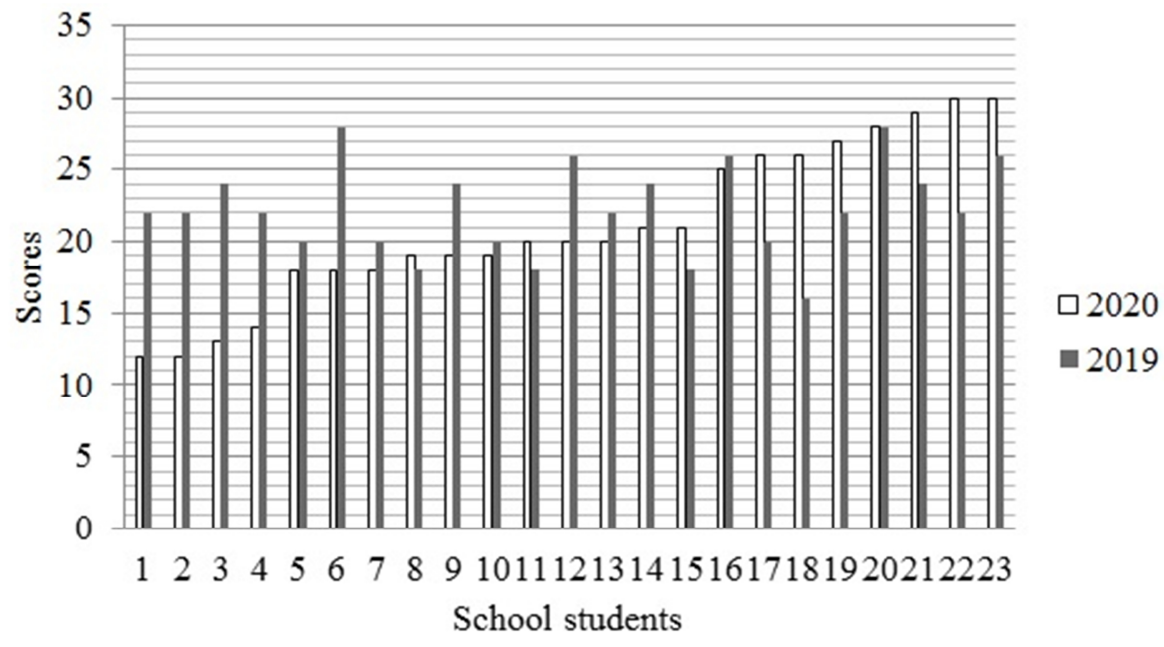

Fig. 1. The distribution of primary points in 2019 and 2020.

Parents noted an increase in motivation with a sufficiently high initial value as stable (Fig. 2). It can be concluded that, regardless of the subject area, respondents evaluated the impact of the procedure on the development of educational motivation.

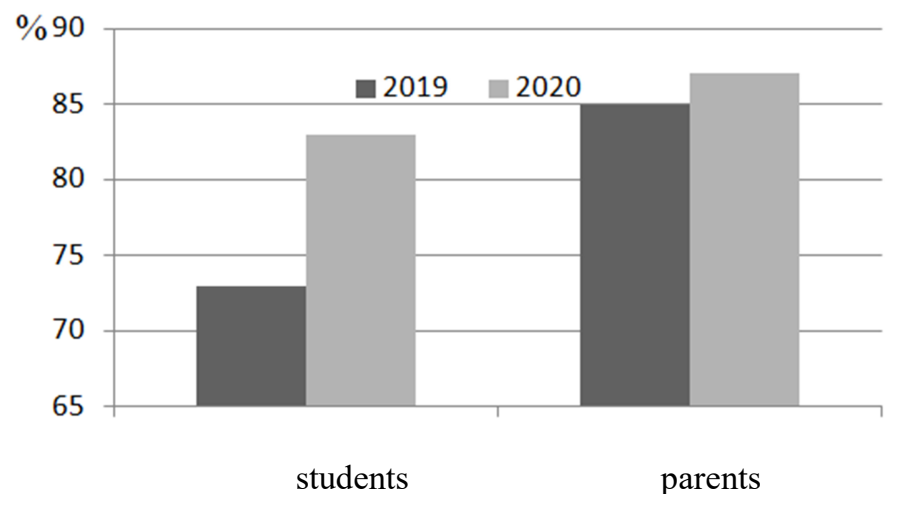

Fig. 2. Assessment of educational motivation after external testing.

This result is primarily due to the fact that an external testing center during automated verification of results, data on students' academic achievements are quickly processed, converted into user-accessible formats, structured, presented understandable for achievement analysis, and transferred to all control participants for analysis and selfassessment of achievements. Therefore, everyone was able to evaluate themselves in the same type of subjects to see detailed information about their achievements and problems, to understand what actions should be taken for further work. 


\section{Discussion of the results}

One of the factors influencing testing on educational motivation is the students' confidence in the grades obtained and their timely analysis, which provides the conditions for introspection. It is self-analysis of objective assessments of the development of the content of the subject area among students that increases the motive for acquiring knowledge and manifests itself as an aspect of personal development. A critical analysis of the grades makes the student admit that if, under the same standardized testing conditions for all participants, he did not get the desired result, then he has his own problems in preparedness. Another factor in increasing educational motivation is the competitiveness of students, so it is important to ensure the reliability, validity and comparability of grades in the assessment process. With confidence in assessment, students develop a value-semantic attitude to the knowledge gained, information is interpreted on an individual-personal level, and skills are developed to use and apply the knowledge most universally. The assessment, obtained independently from the teacher under the same conditions for all subjects, acts as constructive feedback, ensuring the development of a number of personal characteristics of students, such as self-control, self-observation, self-education and increased motivation to achieve individual goals. Skills are worked out with test materials and technologies, oversubject skills are formed, which is especially important when preparing for the unified state exam.

The significance influences on modern forms of assessment, as noted by Ignatyev E. $\mathrm{Yu}$., Is associated with a radical change in the requirements for assessment activities in educational standards [15], which also requires changes in assessment activities, and the translation of the modern approach from the theoretical field into the practical one. New forms can eliminate the influence of negative assessment factors on educational motivation: distrust of the quality of assessment tools, the subjectivity of the teacher in the assessment, lack of information about the work, lack of scaling work results, etc.

Currently, the theory and practice of pedagogical measurements offer a wide range of objective methods for assessing academic achievement. So, for example, the evaluation procedure itself by means of standardized testing is a developing and motivating component as a learning technology that helps to master the techniques and methods in preparation for the final certification. In general education, there is a great need to create a holistic system of training, development, self-monitoring, monitoring, analysis and interpretation of the results both for assessing the quality of preparedness of students and for managing the educational process. The presence of reasonable indicators and evaluation criteria, the transparency of the mechanisms and results of the assessment provide wide informing of interested parties about the results obtained and allow us to draw conclusions about the identified difficulties and plan actions to overcome them.

And, therefore, in order to increase the efficiency and development of quality management forms of the educational process according to the objective results of achievements, it is important to understand what techniques and methods of the modern assessment process are, how they influence the motivational sphere of students in order to achieve the most effective learning and cognitive activity of students.

\section{References}

1. N. Efremova, Educational Researcher 9(2), 911-924 (2018)

2. V. Kraevsky, Bulletin of the Institute for Human Education 2, 1-4 (2011)

3. V. Zvonnikov, A. Malygin, M. Chelyshkova, University proceedings. Humanities Series 5(2), 166-171 (2012) 
4. M. Barber, K. Donnelly, S. Rizvi, Institute for Public Policy Research 72 (2013)

5. T. Gordeeva, E. Shepeleva, Bulletin of Moscow University 3, 33-45 (2011)

6. R. Boyatzis, Encyclopedia of Personality and Individual Differences. Springer 1-3 (2017) doi: 10.1007/978-3-319-28099-8_2230-1

7. N. Pavlova, Physical and Mathematical Education 3(9), 71-76 (2016)

8. D. López-Fernández, J. Ezquerro and others, Acta Astronautica 165, 344-354 (2019)

9. L. Gnezdilova, M. Gnezdilov, Scientific and methodological electronic journal "Concept" 31, 1246-1250 (2017)

10. T. Partovi, M. Razavi, Learnibg and Motivation 68, (2019) doi: 10.1016/j.lmot.2019.101592

11. M. Gordan, International Journal of Research in Education Methodology 5(3), 680-688 (2014)

12. N. Efremova, A. Huseynova, EC Psychology and Psychiatry 11, 72-76 (2019)

13. N. Efremova, Russian Psychological Journal 2, 227-244 (2017) doi: 10.21702 / rpj.2017.2.2.13

14. V. Bolotov, I. Waldman, G. Kovaleva, M. Pinskaya, Education management: theory and practice 2, 57-78 (2011)

15. E. Ignatieva, Continuing Education: XXI Century 3(23), 1-13 (2018) doi: 10.15393 / j5.art.2018.4067. 